\title{
Percepções de professores de Química do nível médio sobre problema e exercício
}

\author{
Perceptions of high school chemistry teachers about problem and \\ exercise
}

\author{
Amanda Pereira de Freitas ${ }^{1}$ \\ Angela Fernandes Campos ${ }^{2}$
}

\section{Resumo}

A presente pesquisa relata uma investigação com professores de Química do ensino médio das escolas públicas de Recife-PE,que teve por objetivo identificar e analisar as percepções desses docentes acerca dos termos problema e exercício. Para tanto, foi realizada uma entrevista semiestruturada com cada docente, a qual mediada por um questionário. O tratamento dos dados foi realizado à luz da Análise de conteúdo proposta por Bardin. Os resultados mostraram que a maioria dos professores tem uma visão simplista acerca de problema não levando em consideração alguns aspectos que são inerentes a um problema. Apenas dois docentes apresentaram uma visão mais ampla sobre problema, considerando o seu ponto de vista metodológico. Além disto, os sujeitos possuem uma percepção inadequada sobre problema e exercício apresentando confusão em relação a distinção destes termos. Em contrapartida, a percepção apresentada pela maior parte dos sujeitos sobre exercício corrobora com as ideias de autores da área de resolução de problemas. O estudo sugere proposição de formação continuada que envolva reflexões sobre o ensino e aprendizagem baseado na resolução de problemas.

Palavras chave: resolução de problemas; exercício; ensino de química

\begin{abstract}
The present research reports an investigation with Chemistry teachers of public high school of Recife, Pernanbuco, Brazil, that aimed to identify and analyze the perceptions of these teachers about the terms problem and exercise. For that, a semi-structured interview was conducted with each teacher mediated through a questionnaire. The treatment of the data was carried out in the light of the Analysis of Content proposed by Bardin. The results showed that most teachers have a simplistic view about problem not taking into account some aspects that are inherent in a problem. Only two teachers presented a broader view of the problem, considering their methodological point of view. In addition, the subjects have an inadequate perception about problem and exercise presenting confusion regarding the distinction of these terms. In contrast, the perception presented by most of the subjects about exercise corroborates with the ideas of authors of the area of problem solving. The study suggests a proposal for continuing education that involves reflections on teaching and learning based on problem solving.
\end{abstract}

Keywords: problem solving; exercise; chemistry teaching

\footnotetext{
${ }^{1}$ Universidade Federal Rural de Pernambuco | amandafreitaspd@gmail.com

2 Universidade Federal Rural de Pernambuco | afernandescampos@gmail.com
} 


\section{Introdução}

A abordagem de ensino e aprendizagem por resolução de problemas constitui-se uma grande tendência teórico-metodológica inserida no campo da Didática das Ciências (CACHAPUZ et al, 2001). O princípio desta abordagem está na proposição de situações problemáticas contextualizadas, de modo que o aluno ao buscar por soluções (uma ou mais respostas), possa desenvolver o aprendizado dos conteúdos envolvidos, utilizando diferentes habilidades e competências que são fundamentais para a educação científica do discente. Desta forma o objetivo da resolução de problemas é fazer com que o aluno resolva problemas como forma de aprender (POZO, 1998).

No ensino de Química a resolução de problemas é uma abordagem didática que vem se configurando como uma linha de investigação no decorrer dos últimos anos (FERNANDES, 2014; FREITAS e BATINGA, 2015; FREITAS, BATINGA e CAMPOS, 2017). Vários estudos (QUÍLEZ, 2006; MOLINÉ, 2007; GOI e SANTOS, 2009; FERREIRA, HARTWING e OLIVEIRA, 2010; LOPES et al, 2011; LACERDA, CAMPOS e MARCELINO-JR, 2012; FERNANDES e CAMPOS, 2013; FERNANDES e CAMPOS, 2014; JUNIOR e NETO, 2015; FERREIRA, FERNANDES e CAMPOS, 2016) têm apontado o uso desta abordagem em sala de aula como uma estratégia didática capaz de promover o ensino dos conteúdos químicos de forma motivadora e contextualizada proporcionando uma aprendizagem ativa e significativa aos alunos.

Esta abordagem também é uma das propostas das novas Diretrizes Curriculares Nacionais (BRASIL, 2015). De acordo com estas Diretrizes, as instituições de ensino superior devem conduzir os docentes em formação inicial e continuada, para a realização de dinâmicas pedagógicas que contribuam para o exercício profissional e o desenvolvimento do professor através de ações didático-pedagógicas que possibilitem condições para o exercício do pensamento crítico, para a resolução de problemas, para o trabalho coletivo e interdisciplinar, para a criatividade, inovação, bem como a liderança e a autonomia (BRASIL, 2015).

Cabe salientar que os problemas trabalhados nesta abordagem didática são diferentes das atividades de exercício. Sendo assim, para que a estratégia de resolução de problemas venha a ter sucesso em sala de aula, faz-se necessário que os significados dos termos problemas e exercício, assim como suas diferenças, estejam bem claras e definidas pelo professor (POZO, 1998), uma vez que problemas e exercícios são ferramentas bastante utilizadas pelos docentes em diferentes situações de ensino e aprendizagem.

Sob esta perspectiva, ao realizarmos uma revisão de literatura em vinte e três (23) periódicos científicos ${ }^{3}$, em um recorte temporal de treze (13) anos (2003 a 2016), observamos que dos quarenta e dois (42) artigos encontrados apenas dois (2) trazem

\footnotetext{
${ }^{3}$ Os periódicos analisados foram: Ciência e Educação, Educação e Pesquisa; Enseñanza de las Ciencias; Revista Brasileira de Pesquisa em Educação em Ciências (RBPEC); Pro-Posições; Educação em Revista; Ensaio: Pesquisa em Educação em Ciências; Investigações em Ensino de Ciências (IENCI); Revista Electrónica de Enseñanza de las Ciencias (REEC); Acta Scientiae; Alambique; Ciência \& Ensino; Ciência em Tela; Experiências em Ensino de Ciências (EENCI); Revista Brasileira de Ensino de Química (ReBEQ); Perspectiva; Revista Brasileira de Ensino de Ciência e Tecnologia (RBECT); Química Nova na Escola (QNesc); Amazônia - Revista de Educação em Ciências e Matemáticas; Química Nova (QN); Rencima - Revista de Ensino de Ciências e Matemática; Revista de Educação; Ciências e Matemática e Revista Debates em Ensino de Química (REDEQUIM).
} 
especificamente uma discussão sobre as concepções de professores de Química acerca de problema e exercício, a saber, os estudos de Freire e Silva (2013) e Soares, Fernandes e Campos (2016). Entretanto, estas discussões estão direcionadas para o contexto da formação inicial. Deste modo, nenhum trabalho no cenário da formação continuada sobre esta temática foi encontrado ao longo deste período.

Diante da relevância da resolução de problemas para o processo de ensino e aprendizagem das Ciências, em especial da Química, e da importância da compreensão dos significados de problema e exercício pelos professores em exercício, formulamos a seguinte questão de pesquisa:

Quais as percepções de professores de Química da Educação Básica sobre os termos problemas e exercício? Partindo desta questão o nosso objetivo foi identificar e analisar quais sentidos estes docentes atribuem a estes termos e quais as principais características de problema e exercício apontadas por eles.

\section{Problema e exercício: diferenças e características}

Nas salas de aulas de Química comumente encontramos professores apresentando "problemas" aos seus alunos para serem resolvidos logo após a exposição dos conteúdos. Estes problemas geralmente são questões corriqueiras utilizadas para que os alunos possam aplicar o conhecimento "aprendido" nas aulas teóricas e também como forma de verificar a aprendizagem perante o conteúdo que foi ensinado. A solução destes problemas é por vezes conhecida, limitando-se a aplicação de fórmulas Químicas e de cálculos matemáticos.

De acordo com Lopes (1994), no campo da Didática das Ciências, esta concepção de problema no âmbito escolar é caracterizada como exercício. Quando o professor propõe uma atividade para os estudantes que se apoia no uso de habilidades e rotinas automatizadas resultantes de práticas consecutivas, isto é entendido como exercício e não como problema.

A fim de clarificarmos as diferenças entre estes termos apresentamos nos quadros 1 e 2 algumas concepções de problema e exercício apresentadas por Pozo (1998). A partir destas definições elencamos algumas características que posteriormente foram utilizados para categorizar os dados obtidos nesta pesquisa.

Pelo exposto nos quadros 1 e 2 é possível perceber que problema e exercício não compõem a mesma tarefa, diferindo em muitos aspectos. Enquanto que os exercícios se caracterizam por serem atividades de prática, cujo caminho para solução é conhecido, marcado pelo uso de fórmulas e conceitos químicos, a tarefa de resolver problemas exige mais do aluno, desenvolvendo o seu raciocínio, proporcionando a ele a construção e a compreensão dos conteúdos químicos, além dos conhecimentos procedimentais e atitudinais. 
Quadro 1. Definições de problema segundo Pozo (1998) e suas características.

\begin{tabular}{|c|c|}
\hline Definições de Problema apresentadas por Pozo (1998) & Características de Problemas \\
\hline $\begin{array}{l}\text { Uma situação para qual não há um caminho de resolução } \\
\text { preestabelecido }{ }^{4} \text {, cujos passos possam ser aprendidos e } \\
\text { aplicados de forma quase automática, e sim que se trata sempre } \\
\text { de questões cuja resposta deve ser, necessariamente explorada. }\end{array}$ & $\begin{array}{l}\text {-Não apresenta um caminho de } \\
\text { resolução preestabelecido; a } \\
\text { solução deve ser explorada. }\end{array}$ \\
\hline $\begin{array}{c}\text { Uma situação que um indivíduo ou um grupo quer ou precisa } \\
\text { resolver e para qual não dispõe de um caminho rápido e direto } \\
\text { que leve à solução. }\end{array}$ & $\begin{array}{l}\text { - Situação que precisa ser } \\
\text { resolvida } \\
\text { - Não possui um caminho rápido } \\
\text { e direto para a solução }\end{array}$ \\
\hline $\begin{array}{l}\text { Tarefas sem uma resposta única, a qual pode ser alcançada por } \\
\text { itinerários diferentes. }\end{array}$ & $\begin{array}{l}\text { - Apresenta vários caminhos } \\
\text { para a resolução }\end{array}$ \\
\hline $\begin{array}{l}\text { Situação problemática num contexto real. A solução de } \\
\text { problemas representa para o aluno uma demanda cognitiva e } \\
\text { motivacional maior do que a execução de exercícios. }\end{array}$ & $\begin{array}{l}\text { - Situação Motivacional e } \\
\text { Contextualizada }\end{array}$ \\
\hline $\begin{array}{c}\text { São exigidas estratégias, conhecimentos conceituais, atitudes, etc. } \\
\text { Exige o uso de estratégias e a tomada de decisões sobre o } \\
\text { processo de resolução que deve ser seguido. }\end{array}$ & $\begin{array}{l}\text { - Situação que exige o uso de } \\
\text { estratégias e um processo de } \\
\text { reflexão para resolução }\end{array}$ \\
\hline
\end{tabular}

Quadro 2. Definições de exercício segundo Pozo (1998) e suas características

\begin{tabular}{|c|c|}
\hline Definições de Exercício apresentada por Pozo (1998) & Características de Exercício \\
\hline $\begin{array}{c}\text { Utilizamos mecanismos que nos levam, de forma imediata, à } \\
\text { solução. }\end{array}$ & $\begin{array}{c}\text { - Caminho rápido e direto para } \\
\text { solução }\end{array}$ \\
\hline $\begin{array}{c}\text { A realização de exercícios se baseia no uso de habilidades ou } \\
\text { técnicas sobreaprendidas, ou seja, transformadas em rotinas } \\
\text { automatizadas como consequência de uma prática continua. }\end{array}$ & $\begin{array}{c}\text { - Utilização de habilidades ou } \\
\text { técnicas preestabelecidas }\end{array}$ \\
\hline $\begin{array}{c}\text { Exercitar uma técnica quando enfrentamos situações ou tarefas } \\
\text { já conhecidas, que não representam nada de novo e que, } \\
\text { portanto, podem ser resolvidas pelos caminhos ou meios } \\
\text { habituais. }\end{array}$ & - Praticar o que foi aprendido \\
\hline
\end{tabular}

4 As palavras e expressões grifadas nos quadros 1 e 2 foram utilizadas para auxiliar todo o processo de interpretação, categorização e análise. 


\section{Aspectos metodológicos}

Este estudo é de natureza qualitativa, uma vez que se propôs analisar os dados (a fala e a escrita dos participantes) de forma descritiva e interpretativa, entretanto uma análise quantitativa também foi realizada a fim de facilitar a análise dos dados tornando-os mais claros e objetivos (LÜDKEe ANDRÉ, 1986; OLIVEIRA, 2016).

Os sujeitos de pesquisa foram professores de Química do nível médio de escolas da rede estadual de ensino, localizadas na cidade do Recife, Pernambuco. A coleta dos dados envolveu sete (7) escolas com a realização de uma entrevista semiestruturada com os docentes que ministravam a disciplina de Química nestas instituições de ensino. As entrevistas foram mediadas por um questionário contendo as seguintes perguntas: "O que você entende por problema?" e "O que você entende por exercício?". Todas as escolas selecionadas para este estudo eram participantes do PIBID ${ }^{5}$ de Química da UFRPE. A escolha por estas instituições deu-se devido à sua acessibilidade, uma vez que são parceiras da Universidade como participantes de um programa que visa a melhoria do ensino.

Participaram da entrevista um total de doze (12) professores, entretanto dois (2) deles foram desconsiderados no momento da análise por não se mostrarem disponíveis em contribuir com a pesquisa. Sendo assim, foram analisados um total de dez (10) questionários, doravante denominados de P1 a P10.

\section{Análise dos Dados}

Para análise das respostas dos professores utilizamos a técnica de Análise de Conteúdo (AC) proposta por Bardin (2011). De acordo com a autora, a AC é um conjunto de técnicas de análise das comunicações que visa obter através de procedimentos sistemáticos e da descrição do conteúdo das mensagens, indicadores (quantitativos ou não) que permitam a inferência de conhecimentos relativos às condições de produção/recepção (variáveis inferidas) destas mensagens.

Em outras palavras, Oliveira et al. (2003) apontam a finalidade dessa técnica cujo propósito está em:

Explicar e sistematizar o conteúdo da mensagem e o significado desse conteúdo, por meio de deduç̃̃es lógicas e justificadas, tendo como referência sua origem (quem emitiu) e o contexto da mensagem ou os efeitos dessa mensagem (OLIVEIRA et al., 2003, p. 3 e 4).

Este processo de explicação, sistematização e significação se dá a partir de técnicas fragmentadas, mas que se complementam, para obtenção de um resultado final satisfatório. Tais técnicas compõem as três fases fundamentais da AC determinadas por Bardin (2011): a pré-análise, a exploração do material e o tratamento dos resultados - a inferência e a interpretação.

A pré-análise refere-se a escolha dos documentos que serão analisados, a elaboração de indicadores que fundamentem a sua interpretação e a leitura flutuante destes documentos. Deste modo, realizamos a leitura dos questionários respondidos por meio da

\footnotetext{
${ }^{5}$ PIBID - Programa Institucional de Bolsas de Iniciação à Docência.
} 
transcrição das respostas dos professores que optaram pela gravação de áudio, como também dos questionários que foram respondidos por escrito.

Na fase da exploração do material ocorre a codificação e categorização por meio das unidades de registro que correspondem às unidades de sentidos presentes nos documentos. Tais unidades possibilitam a realização da categorização que tem por finalidade agrupar os dados em função de características comuns. É nesta fase também, que as categorias são definidas a priori ou a posteriori.

Nesta pesquisa fizemos tanto o uso de categorias a priori embasadas no nosso referencial teórico, quanto de categorias a posteriori que emergiram no decorrer da análise. No quadro 3 encontram-se discriminadas as categorias que foram criadas para atingir o objetivo deste estudo.

Quadro 3. Categorias de análise dos dados a partir da técnica de AC (BARDIN, 2011).

\begin{tabular}{|l|l|}
\hline \multirow{4}{*}{ Categorias de Análise } & \multicolumn{2}{|l|}{ Categorias a priori } & Categoria B - Características de Exercício \\
\cline { 2 - 2 } & $\begin{array}{l}\text { Categoria C - Percepção de Problema e Exercício que se aproximam } \\
\text { da Concepção de Pozo (1998) }\end{array}$ \\
\hline \multirow{3}{*}{ Categorias a posteriori } & $\begin{array}{l}\text { Categoria D - Diferentes sentidos de Problema e Exercício abordados } \\
\text { pelos Sujeitos }\end{array}$ \\
\cline { 2 - 2 } & $\begin{array}{l}\text { Categoria E - Percepção de Exercício como forma de avaliar o } \\
\text { aprendizado }\end{array}$ \\
\hline
\end{tabular}

As categorias a priori A, B e C foram estabelecidas a partir das definições de problema e exercício empregadas por Pozo (1998) (cf. quadros 1 e 2). Utilizamos inicialmente este tipo de categoria, pelo fato de que na literatura há diferentes concepções sobre problema e exercício trazidas por diferentes autores que trabalham com a estratégia de resolução de problemas, no entanto estas concepções se assemelham. Sendo assim, escolhemos a perspectiva de Pozo (1998) por se tratar do nosso principal referencial teórico em relação aos termos problema e exercício.

A fase do tratamento dos resultados, a inferência e a interpretação corresponde ao tratamento dos resultados de forma que venha a ser significativa e válida. Para tanto, as inferências e a interpretações dos resultados devem ser fundamentadas com base em referenciais teóricos e algumas operações, como por exemplo, a elaboração de quadros de resultados, diagramas, figuras, etc., para condensar e pôr em destaque as informações fornecidas pela análise. Sendo assim, para este estudo realizamos as inferências e as interpretações dos dados de acordo com o nosso referencial teórico a respeito da abordagem de resolução de problemas, e para sistematizar os resultados fizemos o uso de quadros como explanado a seguir.

\section{Resultados e discussão}

Nos quadros apresentados adiante se encontram discriminadas as categorias, as subcategorias encontradas, suas descrições e unidades de contexto, algumas respostas representativas e as unidades de análise correspondentes às respostas dos sujeitos para 
cada categoria e subcategoria. As palavras e expressões destacadas em itálico nos quadros correspondem às unidades de registros (sentidos) que nos auxiliaram no processo de categorização e interpretação.

Em seguida faremos inicialmente a explanação da análise das categorias a priori pertinentes as características de problema (Categoria A) e exercício (Categoria B) levantadas pelos sujeitos e as suas percepções sobre estes termos que se aproximam da concepção de Pozo (1998) (Categoria C).

\section{Análise das categorias a priori}

\section{Categoria A}

A primeira análise ilustrada no quadro 4apresenta as características do termo problema apontadas pelos docentes.

Ao analisarmos as respostas dos professores, pudemos identificar seis (6) características de problema. As mais citadas foram: A3 (Situação que precisa ser resolvida) e A5 (Não possui um caminho rápido e direto para a solução) ambas com três respostas. No entanto, os professores que mencionaram a característica $A 3$ (P2, P3, P10) não são os mesmos que mencionaram a característica A5 (P4, P6, P7). Deste modo, a percepção dos professores sobre problema mostra-se bastante diversa.

A subcategoria A2, a qual se refere a problema como uma situação cujo caminho para solução é desconhecido pelo aluno, foi a segunda mais citada pelos professores com duas respostas (P1.A2, P3.A2), mesma ocorrência da subcategoria A6, também com duas respostas (P4.A6, P4.A9), que está relacionada ao uso de habilidades e competências para resolução de um problema, estimulando o desenvolvimento do raciocínio do aluno.

As demais características foram mencionadas apenas uma vez por diferentes professores, a saber: problema como uma situação motivacional através da contextualização (P8.A1); a possibilidade de diferentes caminhos para solução de um problema (P6.A4). A presença de todos esses aspectos no enunciado, compõem o que Pozo (1998) chama de "Problema Real". Nos problemas reais, a situação problemática está inserida em um contexto real do aluno, podendo apresentar mais de um caminho para alcançar a solução. O estudante não dispõe de procedimentos automáticos, preestabelecidos, que permitam a solução. Sendo assim, cabe ao aluno a busca por respostas exigindo dele a tomada de decisão e o uso de habilidades.

Ao realizarmos a categorização das características de problema pudemos notar que a compreensão dos professores para este termo ainda é muito superficial. Eles possuem uma vaga percepção sobre o que realmente é um problema escolar. Apenas três (3) professores mencionaram mais de uma característica para problema (P3.A2.A3; P4.A5.A6; P6.A4.A5), dos quais apenas o P4 e P6 apresentaram uma resposta mais aproximada sobre o termo, como veremos mais adiante na Categoria $C$. 
Quadro 4. Características de Problema presentes nas respostas dos professores

\begin{tabular}{|c|c|c|c|}
\hline \multicolumn{4}{|c|}{ Categoria A - Características de Problema } \\
\hline Subcategorias & $\begin{array}{c}\text { Descrição e Unidades } \\
\text { de Registro }\end{array}$ & Unidade De Contexto & $\begin{array}{l}\text { Código de } \\
\text { Análise }\end{array}$ \\
\hline $\begin{array}{c}\text { 1.Situação motivacional e } \\
\text { contextualizada }\end{array}$ & $\begin{array}{c}\text { Problema como uma } \\
\text { situação motivadora, } \\
\text { despertando o interesse } \\
\text { na resolução através da } \\
\text { contextualização. }\end{array}$ & $\begin{array}{c}\text { P8: Problema é "[...]Alguma } \\
\text { coisa que esteja presente no } \\
\text { cotidiano dos meninos [alunos] } \\
\text { e que leve eles a terem interesse } \\
\text { e descobrir né? Como responder } \\
\text { aquele problema". }\end{array}$ & P8.A1 \\
\hline $\begin{array}{l}\text { 2.Situação que } \\
\text { nãoapresentaumcaminho } \\
\text { de } \\
\text { resoluçãopreestabelecido }\end{array}$ & $\begin{array}{c}\text { Problema como uma } \\
\text { situação cuja solução é } \\
\text { desconhecida, a } \\
\text { resposta deve ser } \\
\text { procurada e explorada } \\
\text { pelo aluno. }\end{array}$ & $\begin{array}{c}\text { P3: Problema é "Algo que não } \\
\text { está ainda definido... aquilo que } \\
\text { precisa ser estudado [...]". }\end{array}$ & $\begin{array}{l}\text { P1.A2, } \\
\text { P3.A2 }\end{array}$ \\
\hline $\begin{array}{c}\text { 3.Situação que precisa } \\
\text { ser resolvida }\end{array}$ & $\begin{array}{l}\text { Problema como uma } \\
\text { situação que precisa de } \\
\text { uma solução. }\end{array}$ & $\begin{array}{l}\text { P2: Problema é "Uma situação } \\
\text { que é apresentava para você... } \\
\text { onde você precisa dar uma } \\
\text { solução para ela". }\end{array}$ & $\begin{array}{l}\text { P2.A3, } \\
\text { P3.A3, } \\
\text { P10.A3 }\end{array}$ \\
\hline $\begin{array}{l}\text { 4.Situação que apresenta } \\
\text { vários caminhos para a } \\
\text { resolução }\end{array}$ & $\begin{array}{l}\text { Problema como uma } \\
\text { tarefa que possui um ou } \\
\text { mais caminhos para } \\
\text { alcançar a solução. }\end{array}$ & $\begin{array}{l}\text { P6: Problema é "Algo que você } \\
\text { precisa ter caminhos para } \\
\text { solucionar. Dependendo do } \\
\text { problema você vai encontrar } \\
\text { caminhos, um ou vários para } \\
\text { tentar solucionar [...]". }\end{array}$ & P6.A4 \\
\hline $\begin{array}{c}\text { 5.Não possui um } \\
\text { caminho rápido e direto } \\
\text { para a solução }\end{array}$ & $\begin{array}{l}\text { Problema como uma } \\
\text { situação que apresenta } \\
\text { um obstáculo, o qual } \\
\text { impede a resolução do } \\
\text { problema de forma } \\
\text { imediata. }\end{array}$ & $\begin{array}{c}\text { P4: Problema é "Uma espécie de } \\
\text { desafio [...]". } \\
\text { P6: Problema é "[...] tentar } \\
\text { solucionar essa dificuldade [o } \\
\text { problema]". }\end{array}$ & $\begin{array}{l}\text { P4.A5, } \\
\text { P6.A5, } \\
\text { P7.A5 }\end{array}$ \\
\hline $\begin{array}{l}\text { 6.Situação que exige o } \\
\text { uso de estratégias e um } \\
\text { processo de reflexão } \\
\text { para resolução }\end{array}$ & $\begin{array}{l}\text { O problema exige de } \\
\text { quem tenta solucionar } \\
\text { um processo de } \\
\text { reflexão ou uma } \\
\text { tomada de decisão } \\
\text { (competências) sobre a } \\
\text { estratégia de resolução } \\
\text { que deve ser seguida } \\
\text { (habilidades) exigindo } \\
\text { mais do raciocínio do } \\
\text { aluno. }\end{array}$ & $\begin{array}{c}\text { P4: Problema é "Uma espécie de } \\
\text { desafio onde o estudante usará } \\
\text { de diversas habilidades e } \\
\text { competências para solucionar". } \\
\text { p9:Problema é "[...] é sempre } \\
\text { algo que você vai apontar pro } \\
\text { aluno... uma situação... que o } \\
\text { aluno consegue desenvolver o } \\
\text { raciocínio". }\end{array}$ & $\begin{array}{l}\text { P4.A6, } \\
\text { P9.A6 }\end{array}$ \\
\hline
\end{tabular}

Obs.: A resposta do P5 não aparece neste quadro, pois foi inserida na Categoria D. 


\section{Categoria $B$}

A seguir apresentamos no quadro 5 a análise de conteúdo para o termo exercício.

Quadro 5. Características de Exercício presentes nas respostas dos professores

\begin{tabular}{|c|c|c|c|}
\hline \multicolumn{4}{|c|}{ Categoria B- Características de Exercício } \\
\hline Subcategorias & $\begin{array}{c}\text { Descrição e Unidades } \\
\text { de Registro }\end{array}$ & Unidades De Contexto & $\begin{array}{l}\text { Código de } \\
\text { Análise }\end{array}$ \\
\hline 1.Prática & $\begin{array}{l}\text { Exercício como uma } \\
\text { situação para } \\
\text { praticar/aplicar os } \\
\text { conteúdos }\end{array}$ & $\begin{array}{l}\text { P6: "O exercitar do ponto de vista } \\
\text { escolar pra mim seria aplicar uma teoria } \\
\text { que já teve conhecimento, que já foi } \\
\text { aprendida e colocar em prática [...]". } \\
\text { P9: "Tá relacionado a aplicação daquele } \\
\text { conteúdo [...] Como se aplica aquela } \\
\text { teoria naquela questão". }\end{array}$ & $\begin{array}{l}\text { P2.B1, P3.B1, } \\
\text { P6.B1, P7.B1, } \\
\text { P8.B1, P9.B1, } \\
\text { P10.B1 }\end{array}$ \\
\hline 2.Uso de técnicas & $\begin{array}{l}\text { Exercício como uma } \\
\text { situação cuja solução } \\
\text { pode ser alcançada } \\
\text { através da aplicação } \\
\text { de mecanismos. }\end{array}$ & $\begin{array}{c}\text { P4: "[...] pode ser solucionado com } \\
\text { aplicação de formulas, respostas curtas, } \\
\text { pequenas...". }\end{array}$ & P4.B2 \\
\hline $\begin{array}{l}\text { 3.Caminho rápido } \\
\text { e direto para } \\
\text { solução }\end{array}$ & $\begin{array}{l}\text { A solução de um } \\
\text { exercício se dá por } \\
\text { caminhos rápidos e } \\
\text { diretos. }\end{array}$ & $\begin{array}{l}\text { P4: "Exercício é algo mais aplicado, mais } \\
\text { direto que pode ser solucionado com } \\
\text { aplicação de formulas, respostas curtas, } \\
\text { pequenas". }\end{array}$ & $\begin{array}{l}\text { P4.B3, } \\
\text { P5.B3 }\end{array}$ \\
\hline
\end{tabular}

Obs.: Não se encontram nesta categoria as respostas de P1 e de P7, pois ambas foram classificadas respectivamente nas categorias $\mathrm{D}$ e E apresentadas mais adiante na análise das categorias a

posteriori.

Na categorização de exercício, foi possível perceber que o aspecto mais citado pelos professores foi o uso do exercício como uma situação prática, para aplicar os conteúdos (B1), a qual foi mencionada expressivamente por sete professores (P2.B1, P3.B1, P6.B1, P7.B1, P8.B1, P9.B1, P10.B1). Sendo assim, compreendemos que para a maioria dos docentes entrevistados, o exercício é o momento de aplicação do conteúdo, em que os alunos irão praticar aquilo que foi explanado em sala de aula. Esta percepção dos docentes corrobora com a concepção de Pozo (1998). Segundo ele, os exercícios são tarefas utilizadas para exercitar uma técnica que foi anteriormente adquirida. Nesse sentido, o exercício é habitualmente empregado para operacionalizar conceitos e utilizar mecanismos.

○ uso de mecanismos, como por exemplo, fórmulas, regras, algoritmos, leis e equações químicas, para resolução de um exercício foi citado apenas por um professor (P4.B2). A utilização destes recursos faz com que a solução do exercício ocorra de forma imediata, por caminhos rápidos e diretos (POZO, 1998). Esta outra característica, esteve presente na resposta de dois professores (P4.B3, P5.B3).

Como resultado da análise desta categoria, pudemos concluir que a percepção que os professores têm sobre exercício está mais definida do que problema. A maioria das respostas foram claras e objetivas, especialmente quanto a 'função' do exercício 
(Subcategoria B1). Uma possível explicação para isto pode ser o fato do exercício está imbricado na prática docente desses professores, pois ainda enquanto alunos do nível básico, a tarefa do exercício já fazia parte da sua vivência escolar.

\section{Categoria C}

No quadro 6 encontram-se as respostas dos professores sobre problema e exercício que se aproximaram da concepção de Pozo (1998).

Quadro 6. Respostas dos professores que se aproximam da concepção de problema e exercício abordada por Pozo (1998)

Categoria C - Percepção de Problema e Exercício que se aproximam da concepção de Pozo (1998)

\begin{tabular}{|c|c|c|c|}
\hline Subcategorias & $\begin{array}{c}\text { Descrição e Unidades } \\
\text { de Registro }\end{array}$ & Unidades de Contexto & $\begin{array}{c}\text { Código de } \\
\text { Análise }\end{array}$ \\
\hline $\begin{array}{c}\text { 1. Percepção de } \\
\text { Problema }\end{array}$ & $\begin{array}{c}\text { Respostas que se } \\
\text { aproximam da } \\
\text { concepção de Pozo } \\
\text { (1998) para o termo } \\
\text { problema. }\end{array}$ & $\begin{array}{c}\text { P4: "Uma espécie de desafio onde o } \\
\text { estudante usará de diversas habilidades e } \\
\text { competências para solucionar". } \\
\text { P6: "Algo que você precisa ter caminhos } \\
\text { para solucionar. Dependendo do problema } \\
\text { você vai encontrar caminhos, um ou vários, } \\
\text { para tentar solucionar essa dificuldade". }\end{array}$ & P6.C1 \\
\hline 2. Percepção de \\
Exercício & $\begin{array}{c}\text { Respostas que se } \\
\text { aproximam da } \\
\text { concepção de Pozo } \\
\text { (1998) para o termo } \\
\text { exercício. }\end{array}$ & $\begin{array}{c}\text { P4: "Exercício é algo mais aplicado, mais } \\
\text { direto, que pode ser solucionado com } \\
\text { aplicação de fórmulas, respostas curtas, } \\
\text { pequenas explicações [...]". }\end{array}$ & P4.C2 \\
\hline
\end{tabular}

Na subcategoria C1, as respostas dos professores P4 e P6 são as que mais se aproximam da concepção de problema apresentada por Pozo (1998) sob o ponto de vista metodológico. Suas respostas fazem referência as principais características de um problema: a presença de um obstáculo, desafio ou dificuldade, para o qual tem-se um ou mais caminhos para resolução e que para alcançá-la será necessário o uso de habilidades e competências, exigindo desta forma, a tomada de decisão do aluno sobre o processo de resolução que deve ser seguido.

Apesar do P7 declarar que problema é uma dificuldade, se caracterizando como um obstáculo (P7.A5), sua resposta foi evasiva quanto aos outros aspectos que caracterizam um problema abordados pelo autor. O mesmo acontece nas respostas de P2, P3 e P10, os quais apontaram problema como uma situação que precisa ser resolvida, porém não citaram outras características apresentadas por Pozo.

Na subcategoria C2, entendemos que a resposta mais aproximada da concepção de Pozo sobre exercício foi apenas a do P4, em virtude de sua resposta apresentar mais elementos característicos de um exercício abordado pelo autor, como por exemplo, a solução de forma imediata por caminhos rápidos e diretos, mediante a utilização de técnicas, isto é, pela aplicação de leis e fórmulas químicas. Na categoria B, a resposta do P4 também foi a única classificada em duas subcategorias (P4.B2.B3). 


\section{Análise das Categorias a Posteriori}

Durante a análise das respostas dos professores às duas questões para as categorias a priori, duas outras categorias emergiram, a saber: a Categoria D, correspondente aos diferentes sentidos de problema e exercício abordados pelos docentes e a Categoria $E$ referente a percepção de exercício como uma forma de avaliação do aprendizado.

\section{Categoria D}

Percebemos nas respostas dos professores que alguns deles apresentaram uma certa confusão na compreensão dos termos problema e exercício, como por exemplo, professores que enxergam problema como sendo uma problematização, e que veem exercício como problema e problema como exercício. Por esse motivo, elaboramos a Categoria D para acomodar as respostas desses sujeitos nas subcategorias organizadas no quadro 7.

Na subcategoria D1, percebemos que o professor P1 ao falar o que entende por exercício, menciona algumas características que fazem referência a um problema, como por exemplo, a contextualização dos conteúdos e a presença de um obstáculo para sua solução. Desta maneira, foi possível notar que P1 não apresenta uma percepção clara sobre problema e exercício.

No tocante a subcategoria D2, entendemos que a resposta do P5 para problema remete à metodologia da problematização, apresentando alguns indícios desta abordagem, como por exemplo, o diálogo entre o professor e o aluno através de questionamentos acerca do conhecimento científico (FREIRE, 1975; DELIZOICOV, ANGOTTI e PERNAMBUCO, 2011).

De acordo com Freire (1975), a problematização está associada ao caráter dialógico entre o conhecimento do educador e o dos educandos e tanto a problematização quanto o diálogo são fundamentais para construção do conhecimento. Neste sentido, o P5 ao relatar que problema "seria um questionamento para entender se o aluno está captando o assunto", ele estaria promovendo o diálogo entre o professor e o aluno sobre os conceitos científicos por meio de questionamentos. Delizoicov, Angotti e Pernambuco (2011), apontam que estes questionamentos fazem parte do primeiro momento pedagógico, que deve ser realizado antes de se introduzir os conteúdos para os estudantes. Diante do exposto, a percepção de problema relatada pelo P5 parece estar associada a questionamentos e indagações provocativas, a fim de estimular o diálogo sobre os conteúdos químicos, para que o professor possa compreender as ideias dos alunos a respeito desses conceitos, e não a um problema real como indicado por Pozo (1998).

Em relação a subcategoria D3, três (3) professores (P2, P3 e P6) citaram o termo problema ao enunciarem o que entendem por exercício. Para estes docentes, o exercício é uma forma de resolver e/ou praticar um problema ou uma situação- problema. Nessa perspectiva, o problema não passará de um mero exercício, pois, quando a prática possibilitar a solução rápida e direta de um problema, esta solução se tornará habitual e a tarefa servirá apenas para exercitar habilidades anteriormente adquiridas (POZO, 1998).

De acordo com Pozo (1998), a aplicação do conteúdo e de técnicas anteriormente demonstradas pelo professor e previamente 'aprendidas' pelos estudantes, constituem um meio procedimental importante, porém não é o suficiente para alcançar a solução de um problema. A solução de um problema exige o uso de estratégias e a tomada de decisões 
sobre o processo de resolução que deve ser seguido diferentemente do exercício para o qual os caminhos de resolução já foram preestabelecidos. Assim, o professor ao utilizar um problema para aplicar um conteúdo e praticar uma técnica, estará transformando o mesmo em um exercício. Segundo Ramírez Castro, Gil-Perez e Martinez Torregrosa (1994) o entendimento do professor sobre o que é problema no contexto da Didática das Ciências e sua diferenciação em relação ao exercício influencia em suas ações didático-pedagógicas em sala de aula.

Quadro 7. Respostas dos professores que apresentaram confusão na definição dos termos problema e exercício

\begin{tabular}{|c|c|c|c|}
\hline \multicolumn{4}{|c|}{ Categoria D - Diferentes sentidos de Problema e Exercício abordados pelos sujeitos } \\
\hline Subcategorias & $\begin{array}{c}\text { Descrição e Unidades } \\
\text { de Registro }\end{array}$ & Unidade de Contexto & $\begin{array}{l}\text { Código de } \\
\text { Análise }\end{array}$ \\
\hline $\begin{array}{l}\text { 1. Exercício como } \\
\text { problema }\end{array}$ & $\begin{array}{l}\text { Respostas sobre } \\
\text { exercício que } \\
\text { apresentaram } \\
\text { características de } \\
\text { problema. }\end{array}$ & $\begin{array}{l}\text { P1: "Processo onde serão apresentados } \\
\text { os conteúdos de forma contextualizada } \\
\text { e o aluno consegue visualizar as } \\
\text { dificuldades apresentadas e solucionar } \\
\text { com o auxílio do professor." }\end{array}$ & P1.D1 \\
\hline $\begin{array}{l}\text { 2. Problema como } \\
\text { Problematização }\end{array}$ & $\begin{array}{l}\text { Problema como um } \\
\text { questionamento para } \\
\text { promoção do diálogo } \\
\text { entre o professor e o } \\
\text { aluno sobre os } \\
\text { conceitos. }\end{array}$ & $\begin{array}{c}\text { P5: "O problema seria um } \\
\text { questionamento... uma arguição... um } \\
\text { questionamento pra tentar entender se } \\
\text { o aluno está captando o assunto... se o } \\
\text { aluno está estudando". }\end{array}$ & P5.D2 \\
\hline $\begin{array}{l}\text { 3. Problema como } \\
\text { exercício }\end{array}$ & $\begin{array}{l}\text { Exercício para } \\
\text { solucionar/praticar } \\
\text { um problema. }\end{array}$ & $\begin{array}{l}\text { P2: "O exercício é uma forma de } \\
\text { prática... ou é uma maneira de você } \\
\text { praticar alguma situação problema". } \\
\text { P3: "Então, o exercício em sala de aula } \\
\text { são para que a gente acompanhe o } \\
\text { aprendizado do aluno tirando dúvidas } \\
\text { e resolvendo os problemas que vão } \\
\text { surgindo individualmente". } \\
\text { P6: "O exercitar do ponto de vista } \\
\text { escolar pra mim seria aplicar uma teoria } \\
\text { que já teve conhecimento, que já foi } \\
\text { aprendida e colocar em prática para } \\
\text { solucionar os problemas". }\end{array}$ & $\begin{array}{l}\text { P2.D4, } \\
\text { P4.D4, } \\
\text { P6.D4 }\end{array}$ \\
\hline
\end{tabular}

\section{Categoria $E$}

Além das categorias acima apresentadas pudemos verificar durante a análise, que alguns dos nossos sujeitos apresentaram uma percepção de exercício como sendo uma forma de avaliação do aprendizado do aluno. Em vista disso, criamos a Categoria E para alocar as respostas destes docentes na subcategoria descrita no quadro 8. 
Quadro 8. Percepção dos sujeitos sobre exercício como forma de avaliar o aprendizado

\begin{tabular}{|c|c|c|c|}
\hline \multicolumn{4}{|c|}{ Categoria E - Percepção de Exercício como forma de avaliar o aprendizado } \\
\hline Subcategoria & $\begin{array}{c}\text { Descrição e Unidades de } \\
\text { Registro }\end{array}$ & Unidade de Contexto & $\begin{array}{l}\text { Código de } \\
\text { Análise }\end{array}$ \\
\hline $\begin{array}{c}\text { 1. Exercício } \\
\text { como avaliação } \\
\text { do aprendizado }\end{array}$ & $\begin{array}{c}\text { Exercício como uma } \\
\text { situação para } \\
\text { verificar/acompanhar a } \\
\text { aprendizagem e o } \\
\text { conhecimento do aluno. }\end{array}$ & $\begin{array}{c}\text { P3: "[...] Então, o exercício em sala } \\
\text { de aula são para que a gente } \\
\text { acompanhe o aprendizado do aluno } \\
\quad[. . .] \text { ". } \\
\text { P5: "Para que ele respondesse... pra } \\
\text { que você [professor] percebesse o } \\
\text { nível de conhecimento dele [aluno] } \\
\text { [...]". } \\
\text { P7: "Pra mim seria uma verificação } \\
\text { da aprendizagem, do conteúdo que } \\
\text { foi ministrado... uma verificação } \\
\text { vamos dizer assim... o que o aluno } \\
\text { conseguiu, vamos dizer assim, } \\
\text { assimilar, né? Desse conteúdo que } \\
\text { foi passado." }\end{array}$ & $\begin{array}{l}\text { P3.E1, } \\
\text { P5.E1, } \\
\text { P7.E1 }\end{array}$ \\
\hline
\end{tabular}

Percebemos que os professores P3, P5 e P7 compreendem a tarefa do exercício escolar como uma forma de verificar a aprendizagem do aluno, mensurando o conhecimento aprendido em sala de aula. Em virtude disto, suas respostas foram classificadas na subcategoria E1.

Este entendimento corrobora com o pensamento de Luckesi (2011). De acordo com o autor, os exercícios quando voltados para avaliar a aprendizagem, tem o propósito de possibilitar ao educador e ao próprio aluno, o nível e a qualidade do aprendizado deste estudante. Ou seja, na medida em que o estudante exterioriza na tarefa do exercício, o conhecimento aprendido em sala de aula, permite que o professor verifique e mensure a aprendizagem dos conteúdos escolares desse educando. Ainda segundo Luckesi (2011), o exercício é uma oportunidade para o aluno aplicar os conteúdos e fixá-los. Esta concepção ratifica o parecer de Pozo (1998) no que diz respeito ao uso do exercício para a aplicação dos conteúdos científicos. Em linhas gerais, esta percepção de exercício está associada a uma concepção tradicional do ensino.

\section{Conclusões}

A partir da análise de conteúdo, foi possível notar que a maioria dos professores de química têm uma visão simplista acerca de problema, mencionando apenas uma característica, e uma percepção muito superficial sobre o termo, não considerando outros aspectos que são importantes e que caracterizam o problema como um problema real (Categoria A).

Em contrapartida, a percepção apresentada pela maior parte dos sujeitos sobre exercício(exceto P1), corrobora com as ideias de Pozo (Categoria B e E). Além disso, alguns 
sujeitos demonstraram confusão quanto a distinção dos termos, apresentando uma percepção inadequada, como por exemplo, os professores que enxergam exercício como problema, problema no sentido da metodologia da problematização e problema como exercício (Categoria D).Contudo, constatamos também que dois docentes (P4 e P6) apresentaram uma visão mais ampla sobre problema, considerando o seu ponto de vista metodológico (Categoria C).

De modo geral, os resultados desta pesquisa sinalizam a necessidade de momentos de formação continuada acerca da abordagem de ensino por resolução de problemas para o ensino de Química, com intenção de proporcionar a estes e a outros professores em exercício na educação básica o conhecimento sobre o ensino e aprendizagem por meio da resolução de problemas bem como a distinção entre problema e exercício.

\section{Referências}

BARDIN, L. Análise de conteúdo. Lisboa: Edições 70, 2011.

BRASIL. Conselho Nacional de Educação. Parâmetros Curriculares Nacionais: Ciências Naturais Diretrizes Curriculares Nacionais para a Formação Inicial e Continuada dos Profissionais do Magistério da Educação Básica. Brasília: MEC, 2015.

CACHAPUZ, A.; PRAIA, J.; GIL PÉREZ, D.; CARRASCOSA, J.; MARTINEZ -TERRADES, F. A Emergência da Didáctica como Campo Específico de Conhecimento. Revista Portuguesa de Educação, Braga, v.14, n.1, p.155-195, 2001.

DELIZOICOV, D.; ANGOTTI, J. A.; PERNAMBUCO, M. M. Ensino de Ciências: fundamentos e métodos. São Paulo: Cortez, 4 ed., 2011.

FERNANDES, L. S. Análise de Tendências de Pesquisa sobre a Resolução de Problemas em Química. 2014. 114f. Dissertação. (Mestrado em Ensino das Ciências). Programa de PósGraduação em Ensino das Ciências, Universidade Federal Rural de Pernambuco, Recife, 2014 FERNANDES, L. S.; CAMPOS, A. F. A abordagem de ligação química numa perspectiva de ensino por situação-problema. Enseñanza de las Ciencias, Barcelona, n. Extra, p. 03211-3215, 2013.

FERNANDES, L. S.; CAMPOS, A. F. Elaboração e Aplicação de uma Intervenção Didática utilizando Situação-Problema no ensino de Ligação Química. Experiências em Ensino de Ciências, Mato Grosso, v.9, n.1, p. 37-49, 2014.

FREIRE, M. S.; SILVA, M. G. L. Como formular problemas a partir de exercícios? Argumentos dos licenciandos em Química. Revista Electrónica de Enseñanza de las Ciencias, Espanha, v. 12, n. 1, p. 191-208, 2013.

FREIRE, P. Pedagogia do Oprimido. Rio de Janeiro: Paz e Terra, 1975.

FERREIRA, I. M.; SANTOS, F. L.; CAMPOS, A. F. Abordagem de Ligação Metálica numa Perspectiva de Ensino por Situação-Problema. Revista Brasileira de Ensino de Ciência e Tecnologia, Paraná, v. 9, n. 2, p. 93-107, 2016.

FERREIRA, L. H.; HARTWIG, D. R.; OLIVEIRA, R. C. Ensino experimental de química: uma abordagem investigativa contextualizada. Química Nova na Escola, São Paulo, v. 32, n. 2, p. 101-106, 2010.

FREITAS, A. P.; BATINGA, V. S. T. Análise de aspectos teóricos e metodológicos em algumas pesquisas sobre a resolução de problemas em Química. In: MEMBIELA, P; CASADO, N.; 
CEBREIROS, M. I. La enseñanza de las ciencias: desafíos y perspectivas. Santiago de Compostela: Educación Editora, 2015.

FREITAS, A. P.; BATINGA, V. T. S.; CAMPOS, A. F. Panorama da produção acadêmica sobre resolução de problemas em química em trabalhos apresentados no Encontro Nacional de Pesquisa em Educação em Ciências. Revista Debates em Ensino de Química, Recife, v. 3, n. 1, p. 87-106, 2017.

GOI, M. E. J.; SANTOS, F. M. T. Reações de combustão e impacto ambiental por meio de resolução de problemas e atividades experimentais. Química Nova na Escola, São Paulo, v. 31, n. 3, p. 203-209, 2009.

JÚNIOR, M. S. L. P.; NETO, J. E. S. Situações-problema como Estratégia Didática para o Ensino dos Modelos Atômicos. Revista Brasileira de Ensino de Ciência e Tecnologia, Paraná, v.8, n. 3, p. 181-201, 2015.

LACERDA, C. C.; CAMPOS, A. F.; MARCELINO JR., C. A. C.; Abordagem dos Conceitos Mistura, Substância Simples, Substância Composta e Elemento Químico numa Perspectiva de Ensino por Situação-Problema. Química Nova na Escola, São Paulo,v. 34, n.2, p. 75-82, 2012.

LOPES, J. B. Resolução de problemas em física e química: modelo para estratégias de ensino-aprendizagem. Lisboa: Texto Editora, 1994.

LOPES, R, M.; SILVA FILHO, M. V.; MARSDEN, M.; ALVES, N. G. Aprendizagem baseada em problemas: uma experiência no ensino de química toxicológica. Química Nova, São Paulo, v.34, n.7, p.1275-1280, 2011.

LUCKESI, C. C. Avaliação da aprendizagem escolar: estudos e proposições. 22 ed. São Paulo: Cortez, 2011.

LUDKE, M.; ANDRÉ, M. E. D. A. Pesquisa em educação: abordagens qualitativas. São Paulo: EPU, 1986.

MOLINÉ, M. R. G. Factores que influyeneneléxito de losestudiantes al resolver problemas de química. Enseñanza de lasciencias, Barcelona, v. 25, n. 1, p. 59-72, 2007.

OLIVEIRA, M. M. Como fazer pesquisa qualitativa. Como fazer pesquisa qualitativa. Petrópolis: Vozes, 7 ed., 2016.

OLIVEIRA, E.; ENS, R. T.; ANDRADE, D. B. F.; MUSSIS, C. R. Análise de Conteúdo e Pesquisa na Área da Educação1. Revista Diálogo Educacional, Paraná, v. 4, n. 9, p. 1-17, 2003.

POZO, J. I. (Org.). A solução de problemas: aprender a resolver, resolver para aprender. Porto Alegre: Artmed, 1998.

QUÍLEZ, J. Análisis de problemas de selectividad de equilibrio químico: errores y dificultadescorrespondientes a libros de texto, alumnos y profesores. Enseñanza de las Ciencias, Barcelona, v. 24, n. 2, p. 219-240, 2006.

RAMIREZ CASTRO, J. L.; GIL-PÉREZ, D.; MARTíNEZ TORREGROSA, J. La resolución de problemas de física y de química como investigación. Madrid: CIDE/MEC, 1994.

SOARES, E. C. A.; FERNANDES, L. S.; CAMPOS, A. F. A Resolução de Problemas e Exercícios na Formação de Professores de Química. Revista Debates em Ensino de Química, Recife, v. 2, n. 1, p. 41-52, 2016. 